\title{
Intersecção entre educação física e a filosofia: ensaio para o ensino do esporte e igualdade de gênero no ensino médio
}

https://doi.org/10.11606/issn.1981-4690.v35inespp77-81

\author{
Mateus Henrique Servilha de Lucca* \\ Roberson Augusto Marcomini*
}

*Governo do Estado

de São Paulo, São

Paulo, SP, Brasil.

\begin{abstract}
Resumo
0 processo de ensino e aprendizagem dos esportes na Educação Física escolar tem ocupado grande espaço nas práticas pedagógicas dos docentes nos diversos níveis de ensino. Existe a preocupação pedagógica na quebra de paradigmas do ensino reducionista do esporte, exacerbando a necessidade de priorizar não apenas aspectos técnico-táticos, mas também socioeducativos e histórico-cultural. Uma vivência e apresentação esportiva que não contemple esses referenciais, corre riscos de desmotivar o processo de aprendizagem dos esportes. Sendo assim, a filosofia abre caminhos para a reflexão democrática no esporte e a igualdade de direitos. Pensando em diálogos interdisciplinares e tendo como base estrutural a Base Nacional Comum Curricular (BNCC) e as tendências emergentes da Pedagogia do Esporte, espera-se apresentar e discutir possibilidades pedagógicas interdisciplinares dentro da escola, da Educação Física escolar e Filosofia, consolidando perspectivas que desenvolvam o fenômeno em sua totalidade e de forma democrática. Para isso, organizou-se uma unidade didática em quatro encontros entre as aulas de Filosofia e Educação Física, para identificar, dialogar e discutir a importância da igualdade de gênero no esporte. Em suma, espera-se apresentar possibilidades pedagógicas para abordar o tema dentro do ambiente escolar, e a partir de, motivar novas intervenções que sejam capazes de mobilizar não apenas o conhecimento para as aulas, mas também para além dos muros da escola.
\end{abstract}

Palavras-chave: Interdisciplinar; Escolar; Prática; Social; Pedagógica.

\section{Introdução}

Na última década o esporte posicionou-se como um dos maiores fenômenos socioculturais e democráticos, que corroborado por uma expansão global, desponta-se em um momento de valorizaçáo, sendo elemento integrador nas relaçóes sociais, manifestando-se em multifários cenários, envolvendo diferentes personagens e carregando diversos significados. Significados estes que mostraram a importância da democracia dentro do esporte desde os jogos olímpicos na Grécia Antiga ${ }^{1}$.

O esporte é um dos ricos patrimônios culturais existentes e que a escola é a principal responsável em transmitir às novas geraçóes parte da cultura, parece determinante entender quais as possibilidades pedagógicas para o tratamento do conteúdo no ambiente escolar. É dentro deste denominador comum que a disciplina de filosofia se une com o esporte para mobilizar em defesa dos direitos humanos e da democracia ${ }^{2,3}$.

Problematizando as sociedades contemporâneas e suas rápidas transformaçóes advindas do modo de convivência social, o contexto educativo torna-se um cenário de grandes dificuldades por diversas situaçóes. Fato que se dá pelo movimento acelerado, provocando na produção de conhecimento e democratização da cultura, um cenário de transformaçóes constantes ${ }^{4}$.

Investigando a realidade de algumas escolas, são inúmeros os desafios que percorrem o ambiente de aprendizagem esportivo nas aulas de Educação Física escolar, dentre eles: a prática pedagógica pautada na repetiçấo de gestos técnicos, a exacerbaçáa da competição, a exclusão das meninas e alunos considerados menos habilidosos, entre outras. Todas essas singularidades apresentam-se como limitadores ao aprendizado que deveria ser o mais integrador e humanizado possível. O que nos orienta é a falta de estímulo à igualdade social ou direitos políticos como ocorreu na Grécia Antiga 5 .

Objetivando organizar documentos que orientem os professores, investiu-se em políticas públicas na intenção de organizar currículos para a Educação 
Básica. O governo federal, como já previsto na Constituição de 1988 e na LDB (Lei de Diretrizes e Bases da Educação Nacional) de 1996, apresenta a necessidade de construção de uma base normativa que possuísse um material abrangente e que fosse capaz de contemplar diferentes grupos dentro de toda expansão territorial no Brasil ${ }^{6}$.

A BNCC (Base Nacional Comum Curricular) é um documento de caráter normativo, que tem como objetivo apresentar aprendizagens essenciais para serem desenvolvidas para todos os alunos em cada etapa da escolarização. Esse conjunto orgânico e progressivo de conhecimentos ao longo da vida escolar, assegura aos alunos seus direitos de aprendizagem e desenvolvimento, desde o Ensino Infantil até o Ensino Médio. Em suma, a ideia do documento é apresentar conhecimentos e habilidades essenciais para que todos os alunos tenham direito de aprender ao longo de toda sua vida escolar ${ }^{7}$.

Para que se possa quebrar os paradigmas existentes e compreender o esporte como um fenômeno, é preciso considerar a compreensão de alguns fatores

\section{Desenvolvimento e discussão}

Apresentar aproximaçóes para organização do processo de ensino, aprendizagem e vivência sócio esportivo na escola leva a compreensão balizada a partir de três principais referenciais: a) técnico-tático (pautado no desenvolvimento físico-motor dos alunos, desta forma ligado ao conhecimento dos aspectos práticos da modalidade; b) socioeducativo (ligado aos valores e modos de comportamento, seja dentro ou fora do ambiente esportivo e c) histórico-cultural (ligado aos valores culturais da modalidade, evolução histórica do esporte, tradiçóes esportivos e demais temas que representem um reflexão crítica sobre o fenômeno esportivo) ${ }^{8}$.

Para tanto, espera-se destacar possibilidades pedagógicas para o referencial socioeducativo, haja em vista uma necessidade inicial em dialogar com a BNCC e sua classificação dos esportes. Afirma-se que o ensino do esporte, na esfera que se faça, não cabe de nenhuma maneira a exclusão dos demais referenciais ou a simples preferência por algum referencial. Existe a necessidade de pensar-se no processo de ensino e aprendizagem que dialogue simultaneamente com os três referenciais.

Desta maneira, para colaboração na construção de pressupostos para o ensino das igualdades de essenciais para prática pedagógica. Cada modalidade tem sua própria especificidade, seja por diversos fatores como: regulamentos, tamanho e características do implemento, terreno de jogo e dimensóes diversas. Assim como, a interação de todos esses elementos presentes em cada esporte vai exigir comportamentos e açóes específicas, que determinaram a estrutura e natureza diferenciada ${ }^{1}$.

O debate sobre direitos humanos e democracia não termina na escola, por isso ao abordar o fenômeno esportivo a partir da sua amplitude de possibilidades metodológicas na escola, enfatizando o processo de ensino, vivência e aprendizagem, que agregados a perspectiva educacional permitam a emancipação de professores e alunos. À luz dos pensadores iluminista reverberar as tendências emergentes da Pedagogia do Esporte, espera-se apresentar e discutir os propósitos da pedagogia do jogo como aliada dentro da escola e da Educaçáo Física, ampliando as possibilidades de intervenção e prática pedagógicas, consolidando perspectivas que desenvolvam o fenômeno em sua totalidade e de forma democrática além dos muros.

gênero dentro do ambiente esportivo e social, estabeleceu-se uma interdisciplinaridade a partir de temas e reflexóes apresentadas na disciplina de filosofia. Essa aproximação entre as duas disciplinas curriculares permite aproximar os conhecimentos e experiências de aprendizagem, a fim de construir uma reflexáo crítica perante o tema dentro da comunidade escolar.

Inicialmente, buscando distinguir quais são os conhecimentos prévios dos alunos, estima-se a realização de um encontro diagnóstico para propor e estruturar os temas a serem discutidos com profundidade. Considerada uma ferramenta essencial para as perspectivas de ensino centradas na tática das modalidades, o jogo diagnóstico apresenta a possibilidade de organizar os conhecimentos já adquiridos pelos alunos e hierarquizar a sequência de conteúdos para o referencial técnico- tático?.

Em primeiro momento, estima-se o desenvolvimento de um jogo - preferencialmente um esporte coletivo, onde os conflitos costumam apresentar com mais facilidade - para observar quais são as vivências e realidades apresentadas pelos alunos. Nessa primeira etapa é importante que o professor observe todas as açóes são evidenciadas 
para que a discussão possa ser concretizada no momento posterior.

A partir das limitaçóes e potencialidades é possível formular objetivos de aprendizagem que colabore para elaboração de atividades que visem superar as dificuldades listadas. Para aproximar essa dinâmica de diagnóstico, após esse primeiro momento, as dificuldades listadas também seriam desenvolvidas e discutidas na disciplina de filosofia.

No terceiro momento, seria proposto uma organização de festival esportivo a partir da modalidade desenvolvida baseada nas características do Sport Education. O modelo que conduz ao ensino do esporte de maneira autônoma permite aos alunos organizarem-se em grupos e estabelecer tarefas para organização do torneio. Essa proposta favorece discussóes e diálogos em grupo o que facilita as reflexóes originadas nos temas emergentes a partir do diagnóstico inicial.

Como encerramento da unidade didática, na aula de filosofia os alunos realizam um feedback das açóes e das questóes de igualdade vivenciadas durante as aulas e vivencias. Discutir e debater como foram as divisões das tarefas durante a organização, como foi a participação dos alunos entre outros levantamentos que podem ser mediados pelo professor com a turma.
Fonte: Brasil, 2019.

Fonte: autores.

QUADRO 1 - Competências e habilidades selecionadas para serem desenvolvidas ao longo da unidade didática.

BNCC - Educação Física (área de linguagens)

Competência: Compreender os processos identitários, conflitos e relaçóes de poder que permeiam as práticas sociais de linguagem, respeitando as diversidades e a pluralidade de ideias e posiçóes, e atuar socialmente com base em princípios e valores assentados na democracia, na igualdade e nos Direitos Humanos, exercitando o autoconhecimento, a empatia, o diálogo, a resolução de conflitos e a cooperação, e combatendo preconceitos de qualquer natureza.

Habilidade: Analisar interesses, relações de poder e perspectivas de mundo nos discursos das diversas práticas de linguagem (artísticas, corporais e verbais), compreendendo criticamente o modo como circulam, constituem-se e (re)produzem significação e ideologias.

BNCC - Filosofia (Ciências humanas e sociais)

Competência: Identificar e combater as diversas formas de injustiça, preconceito e violência, adotando princípios éticos, democráticos, inclusivos e solidários, e respeitando os Direitos Humanos.

Habilidade: Analisar situaçóes da vida cotidiana, estilos de vida, valores, condutas etc., desnaturalizando e problematizando formas de desigualdade, preconceito, intolerância e discriminação, e identificar açóes que promovam os Direitos Humanos, a solidariedade e o respeito às diferenças e às liberdades individuais.

A partir da Base Nacional Comum Curricular foi estabelecido quais as competências e habilidade podem ser desenvolvidas para as preposições didáticas apresentadas (Quadro 1). Desta maneira, o documento auxilia na preparação e intervençóes pedagógicas, possibilitando o diálogo interdisciplinar. Importante ressaltar a necessidade de organizaçáo e planejamento entre as duas disciplinas e os respectivos docentes, a fim de que os temas possam ser desenvolvidos de forma conjunta. No quadro abaixo (Quadro 2), apresenta-se os momentos e quais as respectivas açóes para cada encontro em cada disciplina, sendo cada momento equivalente a duas aulas, nesse caso, a unidade didática teria uma duração de duas semanas ou quatro aulas.

QUADRO 2 - Organização da unidade didática interdisciplinar.

$1^{\circ}$ momento: vivência diagnóstica - identificar por meio dos jogos esportivos coletivos possíveis dificuldades na turma em relação ao tema de igualdade.

$2^{\circ}$ momento: dialogar e discutir sobre esse tema dentro da aula de Filosofia, apoiando e conceituando as situações sociais.

Continua 
QUADRO 2 - Organização da unidade didática interdisciplinar.

3o momento: gerenciar um ambiente de aprendizagem mútua e apresentar possibilidade de soluçóes para
interação social positiva por meio da organização de um festival esportivo. Momento importante para caracterizar
a importância de todos os membros da equipe dentro da organizaçáo do festival. Caracterizar a importância das
funçóes e seus respectivos valores.
$4^{\circ}$ momento: feedback das açôes, dificuldades e possibilidades dentro do contexto de organização do festival.
Momento de discutir e relatar os pontos de vistas e expectativas oriundas da prática e vivência.

\title{
Considerações finais
}

Acredita-se que o processo de ensino, aprendizagem e vivência do esporte no ambiente escolar possa proporcionar relaçóes com o tema de igualdade de gênero, adequado as classificaçóes da $\mathrm{BNCC}^{7}$, apresentando-se como uma possibilidade pedagógica. Para isso, entende-se que é necessário criar e organizar ambientes de aprendizagem que estimulem a autonomia dos alunos para despertar sobre o assunto.

Importante considerar que para criação e elaboração de um ambiente que seja capaz de estabelecer aprendizagem significativa precisa estar atrelado aos objetivos de aprendizagem, que podem basear-se-á nos conhecimentos prévios dos alunos e competências e habilidades previstas para o ensino médio.

Desta forma, defende-se uma estruturação e sistematização de um currículo para o ensino do esporte no ambiente escolar que construa possibilidades de desenvolver competências e habilidades essenciais nos jogadores para que possam obter não apenas êxito no jogo, mas também revelar-se perante as questôes socioculturais de maneira crítica e reflexiva, sendo capaz de transportar e reconhecer os valores não apenas para a comunidade escolar, mas para a sociedade como um todo.

\begin{abstract}
Intersection between physical education and philosophy: essay for sports teaching and gender equality in high school

The process of teaching and learning sports in school Physical Education has occupied a large space in the pedagogical practices of teachers at different levels of education. There is a pedagogical concern in breaking paradigms of reductionist teaching of sport, exacerbating the need to prioritize not only technical-tactical, but also socio-educational and historical-cultural aspects. A sporting experience and presentation that does not include these references, takes the risk of discouraging the learning process of sports. Therefore, philosophy opens the way for democratic reflection in sport and equal rights. Thinking of interdisciplinary dialogues and having the Base Nacional Comum Curricular (BNCC) and the emerging trends of Sport Pedagogy as a structural base, it is expected to present and discuss interdisciplinary pedagogical possibilities within the school, school Physical Education and Philosophy, consolidating perspectives that develop the phenomenon in its entirety and in a democratic way. For this, a didactic unit was organized in four meetings between the Philosophy and Physical Education classes, to identify, dialogue and discuss the importance of gender equality in sport. In short, it is expected to present pedagogical possibilities to address the topic within the school environment, and from there, motivate new interventions that are able to mobilize not only knowledge for classes, but also beyond the walls of the school.
\end{abstract}

KeYword: Interdisciplinary; School; Practical; Social; Pedagogical. 


\section{Referências}

1. Galatti LR, Bettega OB, Paes RR, Reverdito RS, Seoane AM, Scaglia AJ. O ensino dos jogos esportivos coletivos: avanços metodológicos dos aspectos estratégico-tático-técnicos. Pensar Prát.2017;20(3).

2. Darido SC. Diferentes concepçóes sobre o papel da Educaçáo Física na escola. Universidade Estadual Paulista. Pró-Reitoria de Graduação. Caderno de formação: formação de professores didática geral. São Paulo: Cultura Acadêmica, 2012. p. 51-75.

2. Impolcetto FM, Darido SC. Sistematização dos conteúdos do voleibol: possibilidades para Educaçáo Física escolar. Rev Bras Ciênc Mov. 2011;19(2):90-100.

3. Bauman Z. Vida líquida. Rio de Janeiro: Jorge Zahar, 2007.

4. Galatti LR, Paes RR. Fundamentos da pedagogia do esporte no cenário escolar. Mov Percep. 2006;6(9).

5. Neira MG, Júnior MS. A educaçáo física na BNCC: procedimentos, concepçóes e efeitos. Rev Motriv. 2016;28(48):188-206.

6. Brasil, Ministério da Educação. Base Nacional Comum Curricular (BNCC), 2019. Disponível em: http://basenacionalcomum. mec.gov.br/abase/. Acesso em: 21 mai 2020.

7. Machado GV, Galatti LR, Paes RR. Pedagogia do esporte: pressupostos para a organização de conteúdos esportivos na escola de tempo integral. In: Nascimento JV, Souza ER, Ramos V, Rocha JCS, organizadores. Educaçáo física e esportes: convergindo para novos caminhos. Coleção temas em movimento, Florianópolis: Editora UDESC, 2015.

8. Borges RM, Gaya ACA, González FJ, Galatti LR. Possibilidades de realização do diagnóstico no ensino dos esportes: uma pesquisa ação com professores de educação física. Motrivivência. 2017;29(50):104-122.

\begin{tabular}{r|r} 
ENDEREÇO & \\
Mateus Henrique Servilha de Lucca & \\
Rua Horácio Campos Barros, 225 & Recebido: 10/12/2020 \\
Jardim Santa Cecília & Aceito: 18/ 12/2020 \\
13480-670 - Limeira - SP - Brasil & \\
E-mail: mateushlucca@gmail.com & \\
mateus.lucca@etec.sp.gov.br &
\end{tabular}

